\title{
1971: Economic Outlook and Uncertainties
}

THE ECONOMETRIC MODEL FORECASTS of 1971 that have descended upon a suspecting public appear to be in general agreement that real gross national product (GNP) will increase by about 3 percent for the year as a whole and that the overall rate of inflation (GNP deflator) will fall into the $31 \frac{1}{2-4}$ percent range. The latter would represent a substantial reduction from the 5.2 percent rate of inflation that is now generally expected for 1970. Table 1 contains summary data relating to three of the 1971 econometric forecasts-those produced by Michael K. Evans of Philadelphia Research Associates (Evans), the Research Seminar in Quantitative Economics of the University of Michigan (Michigan), and the Wharton Econometric Forecasting Unit at the University of Pennsylvania (Wharton). ${ }^{1}$

The three models forecast increases in real GNP for the year 1971 ranging from $\$ 20$ billion to $\$ 26$ billion; ${ }^{2}$ all foresee substantial increases in real expenditures on homebuilding, ranging from $\$ 3.1$ billion in the Michigan forecast to $\$ 4.7$ billion in the Wharton forecast. The outlook for spending for business fixed investment is weak in all models, with forecasts ranging from no change in real terms in Wharton to a $\$ 2.9$ billion decline in Evans. There is remarkable agreement on a consumer saving rate of 7.1 percent for 1971, compared with about 7.4 percent in 1970.

1. The figures on the Wharton model presented here are not the "control solution," but are taken from a secondary calculation in which no steel strike is assumed.

2. Unless otherwise noted, dollar figures are in 1958 dollars. 


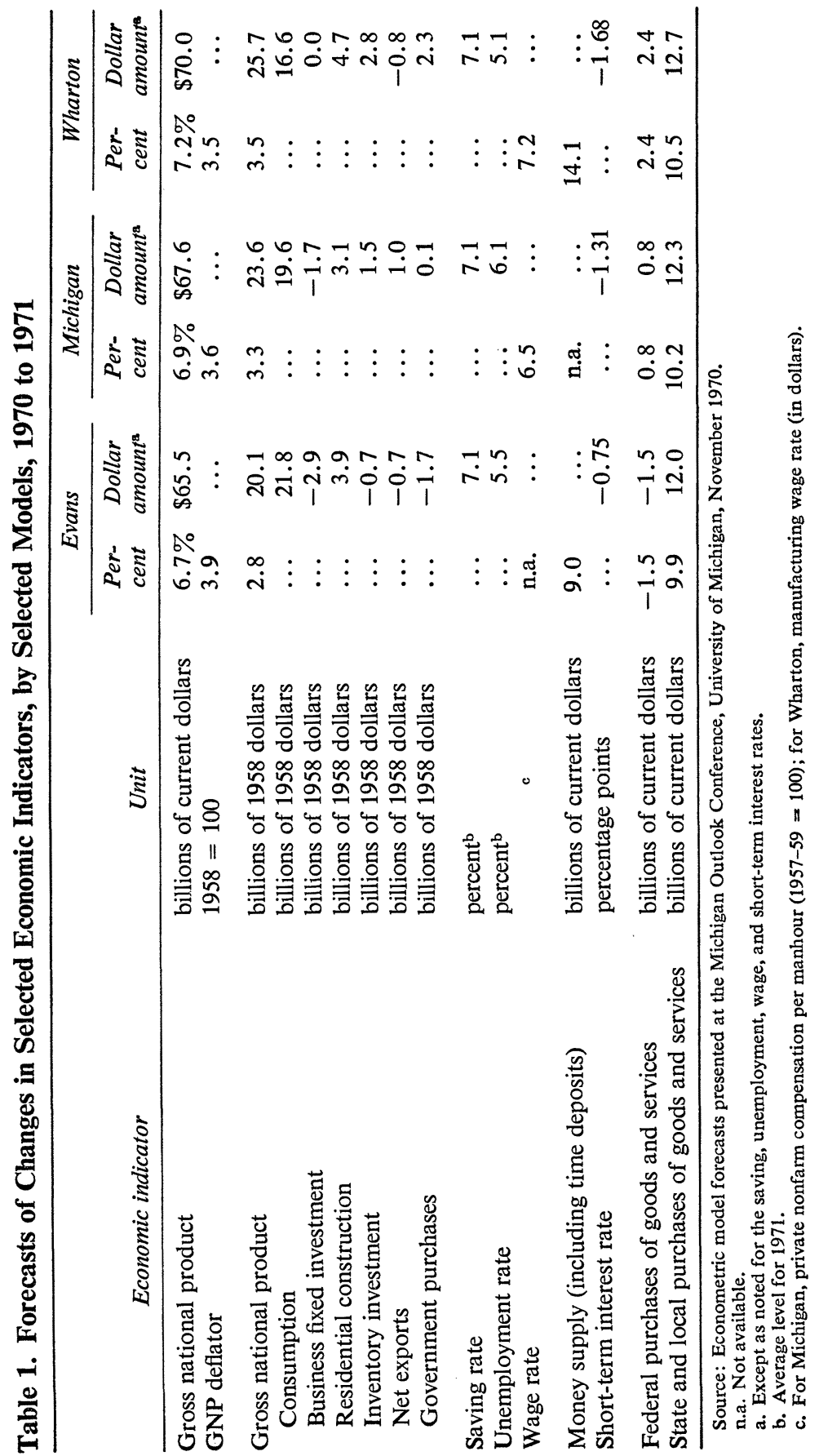


Despite the broad similarities in real output gains, the models differ markedly on the 1971 unemployment rate, with Wharton predicting 5.1 percent, Evans 5.5 percent, and Michigan 6.1 percent. There are also several notable differences in the projection for individual spending sectors. The Wharton model projects an increase of $\$ 2.3$ billion in total real government purchases, while the Evans forecast embodies a decline of $\$ 1.7$ billion, and the Michigan projection shows essentially no change from 1970 . The source of these discrepancies is almost entirely in federal government purchases, principally in the defense sector. Net exports are viewed quite differently, with Michigan forecasting a real increase of $\$ 1$ billion and the other two models a decline of about $\$ 3 / 4$ billion. Finally, short-term interest rates are uniformly projected to decline for the year as a whole, but Evans forecasts a drop of 75 basis points while Michigan and Wharton see declines of around 130 and 170 basis points, respectively.

The contrasts between the models are far more striking when attention is centered on the changes they predict for the year from spring 1971 to spring 1972 (Table 2). The second quarter of 1971 is a useful starting point since the worst distortions from the recent auto strike should be past by then. All the forecasts make the working assumption that there will be no steel strike. On this comparison, Evans and Wharton project a real rate of growth of about 3 percent, while Michigan predicts an increase of $4 \frac{1}{2}$ percent.

The Michigan model's forecast is above the other two for nearly all components, with the most important differences lying in residential construction and inventory investment. The larger consumption gains in the Michigan forecast reflect more rapid advances in household incomes, rather than greater buoyancy in consumer spending propensities. Evans and Wharton have notably different forecasts for some spending components, with Evans projecting more increase in consumption and inventory investment, but less in real government purchases. The latter discrepancy results from different projections of the price deflator. Evans and Wharton foresee similar changes in nominal government purchases, but the Evans inflation rate is a good deal higher than Wharton's so that the real stimulus is much lower in the Evans forecast.

Michigan and Wharton forecast slightly less than 3 percent inflation over the period from spring 1971 to spring 1972, while Evans predicts $31 \frac{1}{2}$ percent. Despite its more rapid growth of output, Michigan has the highest unemployment rate in 1972:2-5.9 percent compared with 5.1 percent in 


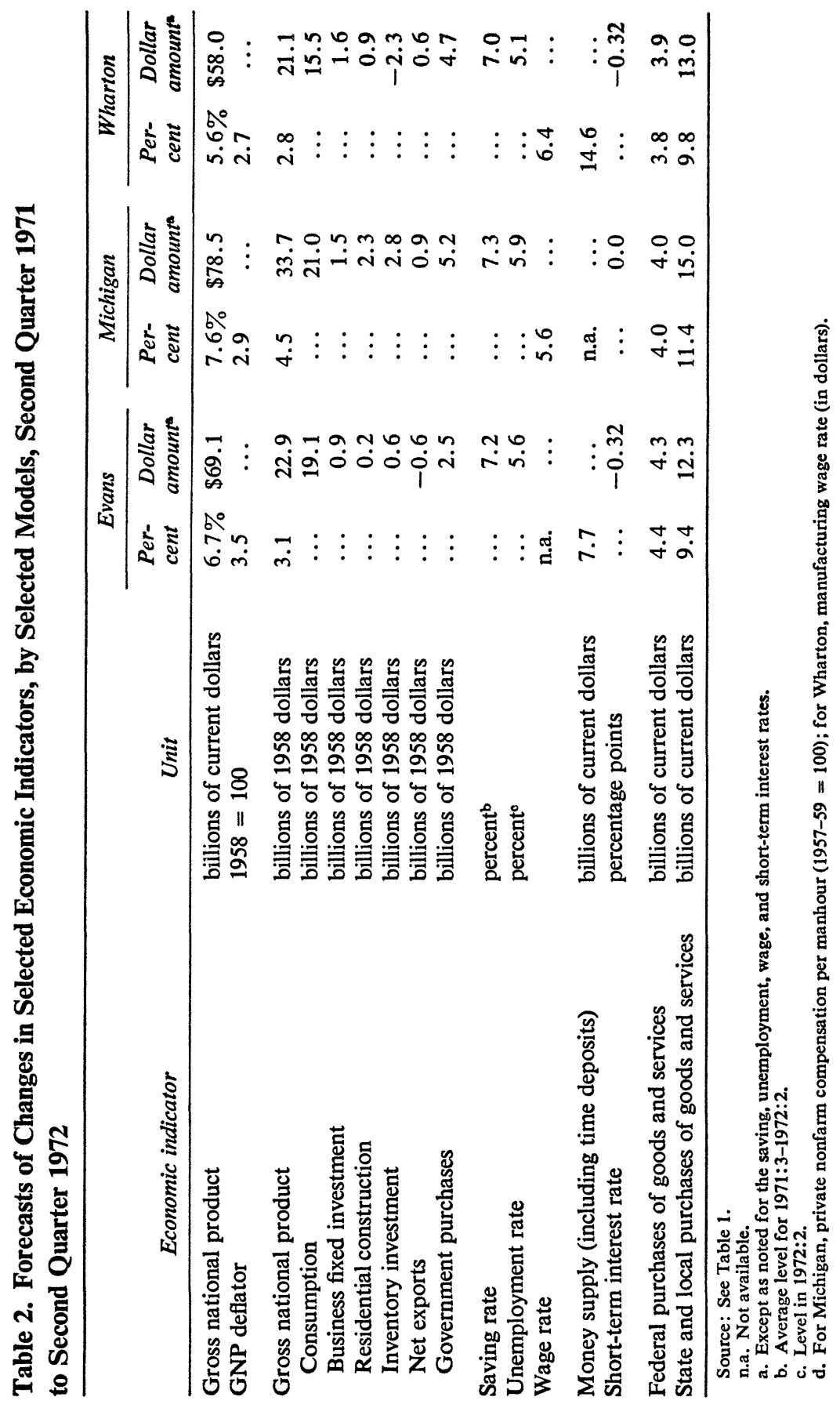


the Wharton forecast. The Wharton model involves a 14.6 percent increase in the broadly defined money supply (which includes time deposits) from spring to spring, while Evans projects a 7.7 percent increase. This difference is not associated with any obvious disparity in the expenditure projections of the two models, presumably because the difference is mainly in the growth of time deposits, which have a small impact on real activity in the Wharton model.

\section{The Areas of Uncertainty}

Based on the views and concerns that seem to dominate discussions among business and academic economists, I see four principal areas of uncertainty:

1. Are consumers about to embark on a spending spree, or will saving rates stay in the neighborhood of $7+$ percent?

2. How strong is the burgeoning upswing in residential building and how much support from monetary policy is required to boost housing starts up to the $13 / 4$ million mark for the year?

3. Will large federal budget deficits, which now seem inevitable in the short run, lead to the traditional conservative response, or will the apparent political liability of high unemployment carry the day and lead to substantial increases in federal spending?

4. Will the Federal Reserve soon decide to stimulate the economy more actively?

The most interesting discussions focus around the last two points. The "responsible conservatives" want to solidify the gains made in the fight against inflation. This group is willing, for the time being, to forgo major attacks on unemployment in order to establish an environment hospitable to the elusive combination of low unemployment and "acceptable" inflation. The "responsible liberals" favor a somewhat more expansive policy in the belief that the unemployment rate will otherwise remain too high for a far longer period than is necessary to establish an "acceptable" inflation rate.

In purely economic terms, there are many ways in which this disagreement can be viewed. First, it may be that the conservatives and liberals are in complete agreement about such objective matters as the feasible combi- 
nations of inflation and unemployment over the near term, and the policies needed to attain any particular combination. This would imply substantial differences in the relative importance attached to employment and price stability by the two groups. On the other hand, they may agree on the relative importance of fighting inflation and unemployment, but disagree about where alternative policies would take the economy in the present situation. Neither of these clean alternatives seems adequate to describe the situation. But I have been struck by some views that seem to be gaining currency. Now that the economy has clearly receded from full employment in an environment that is ever more strongly oriented toward the human aspects of social and economic events, more and more economists seem to question the sanctity of price stability, or the notion that any particular rate of inflation can be classified in an absolute sense as "acceptable" or "unacceptable." Many who believe that the evidence supports the existence of a tradeoff between inflation and unemployment are being drawn to an acceptance of whatever inflation rate turns out to be consistent with some realistic notion of frictional unemployment. And many of these same people seem to be increasing or renewing their attention to various nonbinding incomes policies and longer-term policies designed to shift the Phillips curve to the left - that is, to improve the inflation-unemployment trade-off. In an operational sense, this shift in emphasis reduces the significance of the "accelerationist" debate over whether inflation would grow steadily worse even at a given unemployment rate, if it were allowed to persist without specific counteractive measures.

\section{Summary}

In sum, full agreement has not been reached on the economic outlook beyond the early, strike-dominated quarters of 1971. The economic debate surrounding the outlook is certainly healthy, but the consensus of the forecasting fraternity indicates skepticism that the economy is healthy, given present fiscal-monetary policies. Even the Michigan forecast, which implies well-balanced and broadly based growth after spring 1971, can hardly be viewed as a picture of adequate economic performance. If its predicted $4 \frac{1}{2}$ percent real growth rate is extrapolated forward, full employment is still at least seven years away. At least another full percentage point of annual real growth would be required to attain full employment by 1974 . 


\section{Discussion}

JOSEPH PECHMAN NOTED that most of the GNP forecasts for 1971judgmental as well as econometric-were clustered around \$1,045 billion. These forecasts depend crucially on the assumption that the economy will bounce back to the path toward which it seemed headed before the General Motors strike. They assume a huge rebound in the first quarter of 1971 to the neighborhood of a $\$ 1,020$ billion GNP. Pechman was concerned that evidence of soggy activity in the fourth quarter, generally attributed to the strike, might in reality be pointing to more fundamental weakness, which would imply that the standard forecast was erring on the high side.

Lawrence Klein agreed that the fourth-quarter indicators of economic activity looked weak, but suggested that they had been anticipated in the Wharton model. The strike really did have a number of secondary effects. Alan Greenspan also felt that a GNP rate approaching $\$ 1,020$ billion in the first quarter was credible and, indeed, that it might be achieved from post-strike catch-up even if basic automotive demand is dull.

Hymans explained that the Michigan forecast assumed that two-thirds of GM's production loss would be made up in the first half of 1971. The strike loss is so large that there clearly will be a big bounce in the first quarter and some further make-up in the second. The auto market for calendar year 1971 now looks stronger than it did in September because part of the demand foreseen then for the closing months of 1970 has been moved into the first half of 1971.

Daniel Brill commented that interest rates had dropped so rapidly in October and November that the decline forecast for 1971 by the various models may be largely realized before 1970 ends. He wondered how the forecasts might be updated to take this into account. William Poole was concerned that the very sharp drop in interest rates may be indicating weakness of the economy, as Pechman had suggested.

R. A. Gordon and Robert Solow thought the forecasts of unemployment in the Wharton projection were exceedingly optimistic, given the modest growth of real output in that projection. 